\title{
Les réminiscences spartiates dans les discours et la politique de Robespierre de 1789 à Thermidor
}

The allusions to Sparta in the speeches and politics of Robespierre from 1789 to Thermidor

\section{Maxime Rosso}

\section{(2) OpenEdition}

\section{Journals}

Édition électronique

URL : https://journals.openedition.org/ahrf/11210

DOI : 10.4000/ahrf.11210

ISSN : 1952-403X

Éditeur :

Armand Colin, Société des études robespierristes

Édition imprimée

Date de publication : 1 septembre 2007

Pagination : $51-77$

ISSN : 0003-4436

Référence électronique

Maxime Rosso, «Les réminiscences spartiates dans les discours et la politique de Robespierre de 1789 à Thermidor », Annales historiques de la Révolution française [En ligne], 349 | juillet-septembre 2007, mis en ligne le 01 septembre 2010, consulté le 01 juillet 2021. URL : http:// journals.openedition.org/ahrf/11210; DOI : https://doi.org/10.4000/ahrf.11210 


\title{
LES RÉMINISCENCES SPARTIATES DANS \\ LES DISCOURS ET LA POLITIQUE DE ROBESPIERRE DE 1789 A THERMIDOR
}

\author{
Maxime ROSSO
}

\begin{abstract}
La Grèce antique est une des sources les plus riches de la pensée politique occidentale. Les réflexions de ses philosophes et les institutions de ses cités ont servi de modèles et appuyé les constructions intellectuelles, depuis la fin de cet ancien monde jusqu'au $X X^{e}$ siècle, où, il est vrai, la référence antique s'estompe un peu. Deux systèmes se détachent de l'ensemble et ont retenu l'attention de par leur importance historique et de par l'obstination des auteurs à opposer leurs lois et leurs règles sociales respectives: Athènes et Sparte. On connaît assez bien le lien entre la cité attique et l'idée démocratique. En revanche, l'héritage spartiate est plus difficile à cerner, notamment en France. Pourtant, jusqu'à la fin du XVIII siècle, sur le plan des idées politiques, Lacédémone devance largement sa consœur et fait presque jeu égal avec Rome. Maximilien Robespierre se situe donc au bout de cette chaîne de réflexions autour de la cité de Lycurgue. Il en fait la synthèse et met en avant l'idéal spartiate dans la France révolutionnaire. II peut en effet trouver des exemples et des réponses à ses propres aspirations dans l'histoire de cette cité. La soumission à la loi, la dévotion à la patrie ou la régénération du citoyen grâce à l'éducation, autant de traits qui ont construit la réputation de Sparte. Le contexte révolutionnaire est particulièrement propice à la résurgence de ces valeurs. Robespierre est donc celui qui donne un sens à l'utilisation de Sparte en France de la Renaissance à la Révolution. II montre son rôle dans la construction de l'idée républicaine.
\end{abstract}

Mots-clés : Antiquité, éducation, patriotisme, république, révolution, Robespierre, Sparte.

Depuis qu'on s'intéresse à la pensée politique en Occident, la cité antique de Sparte n'a jamais cessé d'être évoquée. Elle est même, tout comme Athènes, une des rares réalisations politiques et juridiques à devancer les idéaux des auteurs dont nous avons des traces et des souvenirs tangibles en ce domaine. Platon l'a érigée en modèle, Aristote et Isocrate l'ont 
tout à la fois critiquée et louée, à l'époque même où se maintenaient les fameuses institutions de Lycurgue'. Rome, dont le mode de gouvernement, sous sa forme républicaine, pouvait se rapprocher de Lacédémone, redécouvre ces anciennes lois sous les plumes de Polybe et, surtout, de Plutarque $^{2}$. Les références à l'antiquité grecque sont certes moins présentes au Moyen-Âge, mais Sparte revient avec la Renaissance, notamment en Italie où le modèle de la cité-État permet des comparaisons, parfois pertinentes, parfois abusives, avec les républiques anciennes. Lacédémone devient le symbole du régime mixte ${ }^{3}$. En France, Sparte opère son retour par le biais de la pensée protestante, principalement celle des Monarchomaques qui remettent en cause la toute-puissance d'un pouvoir royal catholique défavorable à leurs intérêts en érigeant face à lui l'image des Éphores ${ }^{4}$. Ces magistrats issus de l'élément populaire devaient en effet brimer l'autorité des rois. À partir du XVI siècle, Sparte, soutenue par les nombreuses traductions de Plutarque, va donc tracer son chemin dans notre pays. Bien que discrète au XVII ${ }^{c}$, elle transparaît dans les récits utopiques, où l'on vante les vertus de modèles aristocratiques ${ }^{5}$ ou, plus hardiment, celles de sociétés égalitaires ${ }^{6}$. En tout état de cause, elle vient toujours en appui à l'opposition à l'absolutisme monarchique. C'est avec cette réputation qu'elle aborde les esprits des Lumières. Mably et Rousseau, imprégnés de Plutarque, se chargent de redonner vie au « mythe »

(1) Les ouvrages sur les lois et les institutions spartiates sont très nombreux. On peut se contenter de citer le livre, récent et très complet, d'E. LEVY, Sparte, Histoire politique et sociale jusqu'à la conquête romaine, Paris, Seuil, 2003.

(2) L'idéalisation de Sparte dans l'Antiquité a été mise en relief dans la remarquable thèse de $\mathbf{F}$. Oluter, Le mirage spartiate, 2 vol. réunis, Paris, E. De Boccard, Les Belles Lettres, 1933 et 1943. Cet ouvrage, certes un peu ancien, demeure néanmoins la référence, en langue française, concernant ce sujet et cette période.

(3) Voir notamment E. Rawson, The Spartan tradition in European thought, Oxford, Oxford Clarendon Press, 1991.

(4) Les travaux sont nombreux, on peut citer deux thèses qui donnent une vue d'ensemble : $M$. Marabuto, Les thérories politiques des monarchomaques français, thèse de droit, Paris, 1967 ; H. MoreL, L'idée gallicane au temps des guerres de religion, thèse de droit, Toulouse, 1944, Aix-en-Provence, PUAM, 2003.

(5) Voir l'ouvrage anonyme d'I.D.M.G.T., Histoire du grand et admirable royaume d'Antangil, 1616, ou Les aventures de Télémaque de FÉNELON, 1699.

(6) Voir Denis Vtiras, Histoire des Sévarambes, 1677 (Amiens, Encrage, 1994). 
spartiate et leurs ombres planent sur les hommes de la Révolution qui, devant fonder une république, se parent à nouveau du déguisement antique?

Celui qu'on a nommé l'incorruptible a été un des piliers d'une certaine idée de la Révolution ${ }^{8}$. Il est d'ailleurs demeuré, après sa mort, une des figures de la " gauche » française, jusqu'à ce qu'il soit remplacé par d'autres icônes. Ainsi, même Babeuf, qui l'a un temps combattu, lui reconnaîtra des mérites dans la lutte pour l'égalité et la liberté. Sa permanence depuis 1789 dans le paysage politique permet de témoigner de la constance de ses vues. Sa pensée ne se résume pas à son action, à la « Terreur » et à son culte de l'Être suprême, elle s'analyse aussi au travers de ses discours, fort nombreux au demeurant, qu'ils soient prononcés devant les assemblées représentatives ou le club des Jacobins". La source de son souffle démocratique réside essentiellement dans sa lecture de Rousseau, spécialement Le discours sur l'origine et les fondements de l'inégalité parmi les hommes et

(7) Sur la référence antique sous la Révolution, voir : J. BouINEAU, Les réminiscences de l'Antiquité sous la Révolution française, Montpellier, Speed copic, 4 vol., 1984, Id., Les loges du pouvoir : 1789-1799 ou la Révolution de droit antique, Touiouse, Association des Publications de l'Université de Toulouse-Le Mirail, éd. Eche, Touiouse, 1986, et "Le référent antique dans la Révolution française ", dans M. Ganzin (dir.), $L$ 'influence de l'Antiquité sur la pensée européenne ( $X V T$ - $X X^{\prime}$ siècles), Aix-en-Provence, Centre d'Études et de Recherches d'Histoire des Idées Politiques, Faculté de Droit et de Science Politique d'Aix-Marseille. Presses Universitaires d'Aix-Marseille, 1996, p. 317-337 ; Colloque international de Clermont-Ferrand, juin 1986, Légende de la Révolution, Clermont-Ferrand, Faculté des Lettres et Sciences Humaines Blaise Pascal (Clermont II), Diffusion Adosa, 1988 ; F. Diaz-Plala, Griegos y Romanos, en la Revolucion Francesa, Madrid, Revista de Occidente, 1960 ; J. GODECHOT, "Linfluence de l'Antiquité à l'époque de la Révolution ", Index, 7, 1977, p. 45-67; A. MATHIEZ, Les origines des cultes révolutionnaires, Paris, 1904 ; H. MOREL, "Le poids de l'Antiquité sur la Révolution française ", dans M. GANZIN (dir.), op. cit., p. 295-316 ; D. MORNET, Les origines intellectuelles de la Révolution française, Paris, Réédition de 1927. Armand Colin, 1947 ; C. Mosse, L'Antiquité dans la Révolution, Paris, Albin Michel, 1989 ; H. T. PARKER, The cult of Antiquity and the French revolutionaries : a study in the development of the revolutionary spirit, Chicago, University of Chicago Press, 1937 ; W. Percival, "Greek and Roman history in the French Revolution ", Contemporary Review, 1963, p. 47 à 50 et 155-158 ; R. Recatns, "Quand l'Antiquité inspirait les hommes de la Révolution ", Mélanges Isidore Lévy, Bruxelies, 1955, p. 491-529 ; D. RICHET, " Autour des origines fointaines de la Révolution française "Annales ESC, oct. 1969. Marisa LINTON, The Politics of Virtue in Enlightenment France, New York, Palgrave Macmillan, 2001.

(8) Sur la personnalité et lá pensée de ce personnage, on peut utilement se référer à quelques ouvrages: M. BECKER, Maximilien, histoire de Robespierre, 3 Tomes, Paris, 1989-1999 ; P. BESSAND Massenet, Robespierte : I'homme et l'idée, Paris, De Fallois, 2001 ; M. Bouloiseau, Rohespieme, Paris, PUF, 1956 ; M.N. Bourguet, La référence à l'Antiquité chez Rohespiene et Saint-Just, Mémoire de Maîtrise sous la direction d'Albert Soboul, Université Paris I, 1971 ; F. BRUNEI, Thermidor, la chute de Robespierre, Paris, Complexe, 1989 ; Colloque International de Naples, Images de Robespierre, 27-29 sept. 1993, Naples, Vivarium, 1996 ; Croouez-Loubler, Robespierre, l'Incomaptible, Paris, Scuil, 1984 ; J.P. DOMECO, Robespierre, demiers temps, Paris, Seuil, 1984 ; J.-C. FrerE, Robespierre, la victoire ou la mon, Paris, Flammarion, 1983 ; H. GUll.t.min, Robespierre politique et mystique, Paris, Seuil, 1987 ; G. HEMmERT, Rohespierre l'incomuptible, Paris, Ramsay, 1981 ; LEVIS MIREPOIS, Robespierre prophète de la Révolution, Paris, Perrin, 1978 ; Marand Fouquet, Robespierre et la Révolution, Paris, Denoël, 1989 ; P. Normand, L'énigme Rohespierre, Paris, Amiot-Dumont, 1952 ; J. Ratinaud, Robespierre, Paris, Seuil, 1968 ; SAINTPAulien, Robespierre ou les dangers de la vertu, La Table Ronde, 1984 ; B. SOLlet, Robespierre, Paris, Messidor, 1988.

(9) Marc Bouloiseau ne compte pas moins de cinq cents discours et rapports. Ils ont été réunis sous l'égide de la Société des Études Robespierristes dans une nouvelle édition sous le titre : CEuvres de Maximilien Robespierre, Paris, Phénix, 2000. 
Du contrat social ${ }^{10}$. C'est aussi de là qu'il tire une bonne part de sa vision de l'Antiquité, lorsqu'il ne puise pas directement dans Plutarque, comme la plupart de ses contemporains. Il s'agit en effet de l'auteur ancien le plus traduit en France depuis la Renaissance, et donc le plus populaire". Il a su communiquer, bien des générations plus tard, son enthousiasme pour la morale et surtout pour ce qu'on a pris l'habitude de nommer la vertu, c'està-dire la dévotion et l'abnégation à l'égard du bien public, de la communauté à laquelle on appartient. Il est vrai que le style des Vies des hommes illustres est très accessible et assez plaisant. Aucun auteur français, qu'il soit philosophe, juriste ou penseur politique, n'a pu passer outre. Les Vies, complétées par les recueils moraux des Moralia et des Apophtegmes (ceux des généraux, des rois ou des Lacédémoniennes) contribuent à entretenir le mythe de Sparte : une société idéalement organisée, où les citoyens, complètement désintéressés, sont conduits par la seule vertu.

Les vues de Robespierre sur Sparte ne font pas exception, elles suivent le calque tracé par Plutarque et, plus proche de lui, par Mably, Rousseau, et Barthélémy qui, par son Voyage du jeune Anacharsis (1788) renouvelle l'idéalisation de la cité de Lycurgue. Cependant, ses responsabilités politiques, avec son entrée au Comité de Salut Public, le 27 juillet 1793, lui permettent d'afficher son inspiration, dont il prétend parfois s'écarter. Ses ébauches de réalisation d'institutions font de cette époque l'apogée de la référence spartiate. Mais, très vite discrédité par la « Terreur », cet habit antique se déchire, et Robespierre sera donc le dernier à le porter.

(10) Maximilien de Robespierre, Euvres complètes, Tome X, $5^{c}$ partie, 27 juillet I793-27 juillet 1794, éd. préparée sous la direction de Marc Bouloiseau et Albert Soboul, Publication de la VI Section de l'École Pratique des Hautes Études (Sciences économiques et sociales) et de la Société des Études Robespierristes, Paris, PUF., 1967, Séance du 18 Floréal an Il (7 mai 1794), « Sur les rapports des idées religieuses et morales avec les principes républicains, et sur les fétes nationales ", p. 455 : "Parmi ccux qui, au temps dont je parle, se signalèrent dans la carrière des lettres et de la philosophic, un homme, par l'élévation de son âme et par la grandeur de son caractère, se montra digne du ministère de précepteur du genre humain. Il attaqua la tyrannic avec franchise ; il parla avec enthousiasme de la divinité ; son éloquence mâle et probe peignit en traits de flamme les charmes de la vertu, elle défendit ces dogmes consolateurs que la raison donne pour appui au genre humain. La pureté de sa doctrine, puisée dans la nature et dans la haine profonde du vice, autant que son mépris invincible pour les sophistes intrigants qui usurpaient le nom de philosophes, lui attira la haine et la persécution de ses rivaux et de ses faux amis. Ah ! S'il avait été témoin de cette révolution dont il fut le précurseur, el qui l'a porté au Panthéon, qui peut douter, que son àme généreuse eût embrassé avec transport la cause de la justice et de l'égalité ! ».

(11) Voir notamment : F. HENNEBERT, Histoire des traducteurs français d'auteurs grecs et latins pendant le XVI et le XV7r siècle, Bruxelles, 1861, et J.L. QUANTIN, “Traduire Plutarque d'Amyot à Ricard. Contribution à l'étude du mythe de Sparte au XVIII" siècle ", Histoire, Économie et Société, 1988, p. 243-259. Outre le travail d'Amyot, on peut citer quelques traductions de Plutarque largement diffusées: François TAllemant, Les vies des hommes illustres de Plutarque, nouvellement traduites de grec en françois, par Monsieur l'abbé de T, 6 vol., Paris, 1663-1665 ; Jean Puger DE LA SerRe, L'histoire des hommes illustres de Plutarque, Grecs et Romains, 2 vol., Paris, 1681 ; et surtout les éditions successives de cette même oeuvre par André DActter, agrémentées des remarques de l'auteur, Paris, 1694 (édition incomplète), Paris, 1721 (8 vol.), Amsterdam, 1734 (10 vol.). 


\section{La « démocratie " spartiate}

\section{Une conception de la démocratie entre Rousseau et Montesquieu}

Labolition de la monarchie et la proclamation de la République ne sont qu'une première étape pour Robespierre. Il ne compte pas s'en satisfaire, la Révolution lui apparaît comme l'occasion providentielle de réaliser la démocratie rêvée par Rousseau, son maître à penser. Comme lui, il considère qu'elle ne peut se concevoir autrement que « directe » : « Le peuple veut le bien, parce que le bien public est son intérêt, parce que les bonnes lois sont sa sauvegarde : ses mandataires ne le veulent pas toujours, parce qu'ils veulent tourner l'autorité qu'il leur confie au profit de leur orgueil. Lisez ce que Rousseau a écrit du gouvernement représentatif, et vous jugerez si le peuple peut dormir impunément $\gg^{12}$. Pour lui, le régime représentatif se prête à l'abus. Les députés de la Législative auraient ainsi confisqué la souveraineté en 1792 et exerceraient une autorité quasi-despotique. La classe politique ayant, à ses yeux, besoin d'être régénérée, il prône le renouvellement complet de l'assemblée de la future Convention ${ }^{13}$. Le peuple, s'il ne peut tout faire, comme le reconnaît Robespierre ${ }^{14}$, doit faire preuve d'une grande attention dans le choix et le contrôle de ceux qu'il désigne pour le diriger ou pour porter sa voix. À ce titre, l'Antiquité offre un excellent terrain de réflexion ${ }^{15}$. Les conceptions rousseauistes de la démocratie et de la souveraineté du peuple conduisent Robespierre à l'affirmation d'un fort pouvoir législatif ${ }^{16}$.

(12) M. de Robesplerre, op. cit., Tome VIII, Paris, 1950, Discours, $3^{\mathrm{e}}$ partie, octobre 1791 -septembre 1792, Séance du 2 janvier 1792, « Discours sur la guerre, prononcé à la société des Amis de la Constitution ", p. 90.

(13) Ibid., Séance du 29 juillet 1792, "Sur la déchéance du roi et le renouvellement de la législature ", p. 416 : « Les autres articles sont relatifs à la représentation nationale, dans ses rapports avec le souverain. Et ici, il ne sera question que de relever les bases de la constitution française, déjà renverséc par le despotisme représentatif. La source de tous nos maux, c'est l'indépendance absolue, où les représentants se sont mis cux-mêmes à l'égard de la nation sans l'avoir consultée. Ils ont reconnu la souveraineté de la nation, et ils l'ont anéantie. Iss n'étaient de leur aveu mème que des mandataires du peuple, et ils se sont faits souverains, c'est-à-dire despotes. Car le despotisme n'est autre chose que l'usurpation du pouvoir souverain ".

(14) Ibid., Sćance du 17 pluviôse an II (5 fév. 1794), "Sur les principes de moraie politique qui doivent guider la Convention Nationale dans l'administration intérieure de la Rćpublique ", p. 353 : "La démocratie est un État oủ le peuple souverain, guidé par des lois qui sont son ouvrage, fait par lujmême tout ce qu'il peut bien faire, et par des délégués tout ce qu'il ne peut faire lui-même ".

(15) Ibid., Tome X, Séance du 5 nivôse an II (25 déc. 1793), "Rapport sur les principes du gouvernement révolutionnaire fait au nom du Comité de Salut Public, par Maximilien Robespierre ", p. 277 et 278 : "Élevons nos âmes à la hauteur des vertus républicaines et des exemples antiques. [...] Ô vertu des grands coeurs! Que sont devant toi toutes les agitations de l'orgueil et toutes les prétentions des petites âmes ? Ô vertu, es-tu moins nécessaire pour fonder une république ; que pour la gouverner dans la paix ? $\hat{O}$ patric, as-tu moins de droits sur les représentants du peuple français, que la Grèce et Rome sur leurs généraux ? Que dis-je ? Si parmi nous les fonctions de l'administration révolutionnaire ne sont plus des devoirs pénibles, mais des objets d'ambition, la république est déjà perdue "

(16) Ibid., Tome VIII, Séance du 29 juillet 1792, p. 409 : " Supposez une législature ferme, pure et éclairée ; le pouvoir exécutif n’aurait jamais la puissance de mettre l'État sur le penchant de sa ruine ”. 
C'est ainsi que, de façon très audacieuse, Robespierre fait figurer Sparte, au moins concernant une certaine époque de cette république, parmi les gouvernements démocratiques : "Une nation est vraiment corrompue, lorsqu'après avoir perdu, par degrés, son caractère et sa liberté, elle passe de la démocratie à l'aristocratie ou à la monarchie [...] Lorsqu'après quatre cents ans de gloire, l'avarice a enfin chassé de Sparte les moeurs avec les lois de Lycurgue, Agis meurt en vain pour les rappeler $\gg^{17}$. Aucune autre forme de gouvernement que la démocratie, semble-t-il, ne trouve grâce à ses yeux.

Robespierre redonne vigueur à la théorie de Montesquieu sur les divers régimes, à savoir que si la crainte constitue le fondement de l'État despotique et l'honneur celui de la monarchie, le principe moteur des républiques est bien la vertu. Or, en bon lecteur du baron de la Brède, il aura remarqué que la vertu était plus nécessaire dans une démocratie que dans une aristocratie, celle-ci pouvant se contenter d'asseoir la domination de quelques-uns sur la " modération" qui n'est qu'une partie de la vertu". Ainsi, en faisant de Sparte le dernier refuge de la vertu dans un monde corrompu depuis la nuit des temps, Robespierre atteste la qualité de démocratie de cette cité : "Les siècles et la terre sont le partage du crime et de la tyrannie ; la liberté et la vertu se sont à peine reposées un instant sur quelques points du globe. Sparte brille comme un éclair dans des ténèbres immenses $»^{19}$.

Lorsque Robespierre parle de vertu, il entend ce terme comme tous ses prédécesseurs depuis Machiavel, c'est-à-dire la vertu «publique », qui se manifeste par le civisme et le patriotisme ${ }^{20}$. Le préalable à l'affirmation de ces valeurs, c'est la lutte contre la corruption. Son discours du 17 pluviôse an II (5 février 1794) reflète ce désir de moralisation de la société à tous les niveaux : «Quel est le but où nous tendons ? La jouissance paisible de la liberté et de l'égalité ; le règne de cette justice éternelle, dont les lois ont été gravées, non sur le marbre ou sur la pierre, mais dans les cœurs

(17) Ibid., Tome X, Séance du 17 pluviôsc an 11 ( 5 fév. 1794), p. 354 et $355:$ : Il n'est que la démocratie où l'État est véritablement la patrie de tous les individus qui le composent, et peut compter autant de défenseurs intércssés à sa cause qu'il renferme de citoyens. Voilà la source de lit supériorité des peuples libres sur tous les autres. Si Athènes et Sparte ont triomphé des tyrans de I'Asie [...] il n'en faut point chercher d'autre cause ".

(18) l bid., p. 353 : " Non seulement la vertu est l'âme de la démocratie ; mais elle ne peut exister que dans ce gouvernement $\gg$.

(19) Ibid., Séance du 18 floréal an II (7 mai 1794), "Sur les rapports des idées religieuses et morales avec les principes républicains ", p. 444.

(20) Ibid., Sćance du 17 pluviôse an II (5 fév 1794), p. 353 : " Or, quel est le principe fondamental du gouvernement démocratique ou populaire, c'est-à-dire, le ressort essentiel qui le soutient et qui le fait mouvoir ? C'est la vertu ; je parle de la vertu publique qui opéra tant de prodiges dans la Grèce et dans Rome, et qui doit en produire de bien plus étonnants dans la France républicaine; de cette vertu qui n'est autre chose que l'amour de la patrie et de ses lois ". 
de tous les hommes [...] Nous voulons un ordre de choses où toutes les passions basses et cruelles soient enchaînées, toutes les passions bienfaisantes et généreuses éveillées par les lois; où l'ambition soit le désir de mériter la gloire et de servir la patric ; où les distinctions ne naissent que de l'égalité même ; où le citoyen soit soumis au magistrat, le magistrat au peuple, et le pcuple à la justice ; où la patrie assure le bien-être de chaque individu [...] où toutes les âmes s'agrandissent par la communication continuelle des sentiments républicains et par le besoin de mériter l'estime d'un grand peuple; où les arts soient les décorations de la liberté qui les ennoblit, le commerce la source de la richesse publique, et non seulement de l'opulence monstrueuse de quelques maisons. Nous voulons substituer, dans notre pays, la morale à l'égoïsme [...] un peuple magnanime, puissant, heureux, à un peuple aimable, frivole et misérable, c'est-à-dire, toutes les vertus et tous les miracles de la République, à tous les vices et à tous les ridicules de la monarchic ${ }^{21}$. On remarque l'emprunt fait à Sparte. En effet, Lycurgue avait interdit l'écrit comme support matériel des lois. Il souhaitait lui aussi qu'elles se gravent dans les coeurs par leur pratique constante. Robespierre suit pas à pas le législateur de Lacédémone. Il veut régénérer l'homme, en faire un être conduit par la vertu, entièrement tourné vers l'État. Ce futur citoyen sera également apte à discerner le vrai du faux, en cultivant des valeurs simples et authentiques ${ }^{22}$.

Certes la conclusion de Robespierre tend à marquer son opposition à tout régime monarchique, mais ce discours lui permet d'afficher clairement le modèle antique qui emporte sa préférence : Athènes est délibérément écartée au profit de Sparte, qui ici fait seule figure de véritable démocratie. Lycurgue n'a, pour l'instant, pas d'égal ${ }^{23}$.

À l'instar de la plupart des auteurs depuis l'Antiquité, Robespierre associe la vertu et la frugalité, la seconde étant nécessaire à l'établissement de la première : « [...] la République n'a pour elle que les vertus. Les vertus sont simples, modestes, pauvres, souvent ignorantes, quelquefois grossières ; elles sont l'apanage des malheureux, et le patrimoine du peuple. Les vices sont entourés de tous les trésors, armés de tous les charmes de la volupté et de toutes les amorces de la perfidie ; ils sont escortés de tous les talents dangereux exercés pour le crime $»^{24}$. La richesse est bien évidemment atta-

(21) Ihid., p. 352 .

(22) lbid., Sćance du 18 floréal an II (7 mai 1794), p. 446 : "I e fondement unique de la société civile, c'est la morale ".

(23) Ibid., Tome VIII, Séance du 10 février 1792, "Sur les moyens de sauver l'État et la liberté », p. 157 : "Excepté un trop petit nombre de législateurs anciens, qui cherchèrent dans le cour humain et dans la morale, les bases de la prospérité publique, l'histoire ne nous présente que des charlatans politiques, qui plongent les peuples dans un abîme de malheur et de vices, parce qu'ils dédaignent d'avoir de la probité et du sens commun".

(24) lbid., Tome X, Séance du 5 nivôse an II (25 déc. 1793), p. 278. 
chée à la corruption, elle perturbe aussi la perception des vraies valeurs. La frugalité, à l'inverse, permet de rester à leur contact, de conserver le lien avec le bien public, et donc, selon Robespierre, d'accéder au bonheur de chacun ${ }^{25}$.

À ce titre, la vertu ne peut pas non plus s'écarter de l'égalité. Rousseau n'est jamais bien loin : «Apprenez à goûter les charmes de l'égalité et les délices de la vertu [...] et laissez au peuple, du pain, du travail et des mours ${ }^{26}$. Légalité, pour tout républicain, se traduit, en premier lieu, par la participation à la vie civique et politique.

C'est pourquoi Robespierre monte au créneau, le 11 août 1791, au moment où on discute de la nouvelle constitution à donner à la France, pour affronter les partisans d'un régime censitaire, soutenus par ceux qui désirent arrêter le processus révolutionnaire : "Est-il vrai que la probité, que les talents se mesurent réellement à la fortune ? [...] je dis que les peuples libres ont dédaigné, ont méprisé cette garantie, que les plus grands législateurs de l'humanité l'ont regardé comme une injuste absurdité ; car les plus grands législateurs sont ceux qui ont fondé la législation sur la morale ". Il constate que même les plus grands esprits de ce siècle, inspirateurs de la Révolution, n'auraient pu participer ni aux assemblées ni au processus électoral : "Quelle serait la garantie de Rousseau ? Il ne lui eût pas été possible de trouver accès dans une assemblée électorale. Cependant, il a éclairé l'humanité, et son génie puissant et vertueux a préparé vos travaux. D'après les principes du comité, nous devrions rougir d'avoir élevé des statues à un homme qui ne payait pas un marc d'argent " ${ }^{27}$. Pour Robespierre, la richesse est bien plus le prix du calcul que de la sagesse. La fortune des particuliers ne doit pas entrer en compte dans la vie politique, elle est souvent plus un obstacle qu'un atout dans la poursuite du bien public ${ }^{28}$. La vertu doit demeurer le seul moteur de la révolution en

(25) Ihid., Tome IX, Paris, 1958, Discours (4' Partie), Septembre 1792.27 juillet 1793, "Pour des mesures de salut public ( 8 mai 1793) », p. 488 : " Une partie des défenseurs du peuple s'cst laissée corrompre ; moi aussi, j'aurais pu troquer mon âme contre l'opulence; mais je regarde l'opulence non seulement comme le prix du crime, mais encore comme la punition du crime, et je veux être pauvre pour n'être point malheureux $»$.

(26) Ibid., Séance du 2 décembre 1792, “Opinion de Robespierre sur les subsistances ", p. 117, et Tome X, Séance du 17 pluviôse an II (5 fév. 1794), p. 354 : « Puisque l'âme de la République est la vertu, l'égalité, et que votre but est de fonder, de consolider la République, il s'ensuit que la première règle de votre conduite politique doit être de rapporter toutes vos opérations au maintien de l'égalité et au développement de la vertu [...] Dans le système de la Révolution française, ce qui est immoral est impolitique, ce qui est corrupteur est contre-révolutionnaire ".

(27) Ibid., Tome VII, Paris, 1950, Discours (2 Partie), janvier-septembre 179l, Séance du 11 août 1791, « Discussion du projet de constitution », p. 620 et 621.

(28) Ibid., Tome VIII, Séance du 10 mai 1792, “Sur l'admission des seuls citoyens ayant payé leurs contributions ", p. 347 : "Que signifie donc ce zc̀le de vouloir des quittances d'imposition pour assister à nos séances? Ce titre suffit-il pour être garant du patriotisme? $n$. 
cours et de la démocratie à établir. Robespierre fait remarquer, de surcroît, qu'il serait impossible de maintenir le patriotisme et l'énergie du peuple qui a soutenu la Révolution, et qui en protège les acquis, si on devait totalement l'écarter de la prise de décision ${ }^{29}$.

\section{L'égalité selon Robespierre}

Il réclame donc l'égalité politique. Sur ce point, il s'écarte de l'exemple spartiate, qu'il se permet même de critiquer. Il n'approuve pas la division en castes en vigueur dans cette cité. Il est sensible au sort des hilotes et des autres classes inférieures à celle des Spartiates proprement-dits, les «Égaux »"30, privés des droits civiques les plus élémentaires. Il se sert de cette comparaison antique pour attaquer l'idée de cens électoral, de nouveau débattue en 1793 à propos de la nouvelle constitution. Les Français les plus pauvres deviendraient ainsi les hilotes chargés de nourrir une nouvelle aristocratie formée de bourgeois ${ }^{31}$. C'est une des rares fois où Robespierre déniera le caractère démocratique des institutions spartiates. Si la république de Lycurgue fait souvent figure de parangon dans ses discours, elle n'est pas un aboutissement, la France, instruite par l'histoire, est appelée à dépasser ce modèle : «Mais les Français sont le premier peuple du monde qui ait établi la véritable démocratie, en appelant tous les hommes à l'égalité et à la plénitude des droits du citoyen ; et, c'est là, à mon avis, la véritable raison pour laquelle tous les tyrans ligués contre la République seront vaincus ${ }^{32}$. La constitution de l'an I répond à ce refus de l'inégalité politique issue du système censitaire.

Robespierre ne va pourtant pas jusqu'à demander l'égalité de fait. Il ne s'inscrit pas dans la lignée d'un Morelly ou d'un Mably : "Il ne fallait pas une révolution sans doute, pour apprendre à l'univers que l'extrême disproportion des fortunes est la source de bien des maux et de bien des

(29) Ibid., Séance du 29 juillet 1792, p. 415 : « Dans les grands dangers de la patrie, il faut que tous les citoyens soient appelés à la défendre"

(30) Le terme "Égaux " semble être une traduction abusive du mot " homoioi ", servant à désigner les Spartiates citoyens de plein droit. Il se traduirait plus exactement par " semblables".

(31) M. RoBrSPIERRE, op. cit., Tome IX, "Sur l'obligation de contribuer aux charges publiques (17 juin 1793) », p. 576 : «En effet, si vous décrétez, surtout constitutionnellement, que la misère excepte de l'honorable obligation de contribuer aux besoins de la patrie, vous décrétez l'avilissement de la partic la plus pure de la nation ; vous décrétez l'aristocratie des richesses, et bientôt vous verriez ces nouveaux aristocrates, dominant dans les législatures, avoir l'odieux machiavélisme de conclure que ceux qui ne paient point les charges ne doivent point partager les bienfaits du gouvernement ; il s'établirait une classe de prolétaires, une classe diilotes, et l'égalité et la liberté périraient pour jamais ».

(32) lihid., Tome X, Séance du 17 pluviósc an II ( 5 fév, 1794), p. 354 ; et Tome IX, " Sur la constitution" (15 avril 1793), p. 439 : « La constitution française, telle qu'elle est, est encore la meilleure qui existe dans le monde. Elle est infiniment supérieure, non seulement à celle de tous les peuples qui existent maintenant, mais mème à celles des peuples de l'Antiquité la plus reculée. Car partout vous voyez l'aristocratic consacrée dans de petits territoires, ici vous avez l'égalité des droits absolument consacrês par la constitution existante $n$. 
crimes ; mais nous n'en sommes pas moins convaincus que l'égalité des biens est une chimère. Pour moi, je la crois moins nécessaire encore au bonheur privé qu'à la félicité publique : il s'agit bien plus de rendre la pauvreté honorable, que de proscrire l'opulence ${ }^{33}$. Il n'est pas partisan de l'égalité de biens qui lui semble impossible. Il ne souhaite que réduire l'écart entre riches et pauvres, éviter à la fois l'indigence et l'opulence. Il ne remet pas en cause le droit de propriété, qu'il considère d'ailleurs comme un fondement essentiel de la nouvelle société $e^{34}$, mais il cherche à la désacraliser. Il refuse son caractère absolu, un des premiers acquis de la Révolution, qu'il juge à l'origine de biens des abus. Cet attribut risque de mettre à mal l'autorité de l'État en lui opposant un droit inviolable, inhérent à l'intérêt particulier. Cependant la communauté de biens, que certains ont cru reconnaître dans les institutions lacédémoniennes, ne fait donc pas partie de l'univers robespierriste. Il le dit lui-même, il ne s'agit pas de « jeter la République française dans le moule de celle de Sparte $»^{35}$.

Lexemple spartiate est ostensiblement écarté lorsqu'il s'avère gênant. Robespierre semble même se rallier à tous ceux qui se sont élevés contre la manie antiquisante qui a saisi les hommes de la Révolution. Comme eux, il met en évidence la différence de contexte et la distance entre les grands États modernes et les petites cités de Grèce, spécialement Sparte qui est en réalité la seule république ancienne admirée pour ses institutions (la démocratie athénienne ne commencera à être perçue positivement qu'à partir du XIX" siècle) : «Si quelqu'un croit pouvoir objecter aux vérités que je viens de développer, l'exemple de quelque peuple ancien ; qu'il veuille bien y réfléchir un instant ; il verra qu'il parle d'une petite ville dont les lois étaient fondées sur deux bases qui nous font horreur ; la pauvreté et la communauté de biens ; il verra qu'il n'y a rien de commun entre cette famille de républicains austères, et une nation de vingt-cinq millions d'habitants, dans les circonstances où nous sommes. Il sentira qu'un peuple qui sort du sein de la servitude, pour retomber entre les mains de l'intrigue, doit suivre une autre politique, que celle d'une société dont la liberté est

(33) Ibid., Tome IX, " Sur la nouvelle déclaration des droits (24 avril 1793) m, p. 459.

(34) Ibid., Séance du 2 décembre 1792, p. 112 et 113 : «Quel est le premier objct de la société ? C'est de maintenir les droits imprescriptibles de l'homme. Quel est le premier de ces droits ? Celui d'exister. La première loi sociale est donc celle qui garantit à tous les membres de la société les moyens d'exister ; toutes les autres sont subordonnées à celle-là ; la propriété n’a été instituće ou garantie que pour la cimenter [...] D'après ce principe, quel est le problème à résoudre en matière de législation sur les subsistances ? Le voici : assurer à tous les membres de la société la jouissance de la portion des fruits de la terre qui est nécessaire à leur existence ; aux proprićtaires ct aux cultivateurs le prix de leur industrie, et livrer le superflu, à la liberté du commerce. Je défie le plus scrupulcux défenscur de la proprićté de contester ces principes, à moins de déclarer ouvertement qu'il entend par ce mot le droit de dépouiller et d'assassiner ses semblables ".

(35) Ibid., Tome X, Séance du 17 pluviose an II (5 fév. 1794), p. 354 et 355. 
assise depuis longtemps sur les lois et les mœurs $"{ }^{36}$. Ce que Robespierre apprécie dans Lycurgue, c'est plus son effort de régénération de l'homme que l'établissement d'une société communautaire ${ }^{37}$.

À l'exception de quelques traits qui le rebutent dans Lacédémone, la référence spartiate est abondamment utilisée par Robespierre. Il montre notamment l'utilité du sentiment religieux entretenu dans cette cité, lorsqu'il perçoit les dangers pour l'autorité étatique de laisser répandre l'athéisme dans le pays : «Aussi je ne sache pas qu'aucun législateur se soit jamais avisé de nationaliser l'athéisme. Je sais que les plus sages mêmes d'entre eux se sont permis de mêler à la vérité quelques fictions, soit pour frapper l'imagination des peuples ignorants, soit pour les attacher plus fortement à leurs institutions. Lycurgue et Solon curent recours à l'autorité des oracles [...] Léonidas aux Thermopyles, soupant avec ses compagnons d'armes, au moment d'exécuter le dessein le plus hérö̈que que la vertu humaine ait jamais conçu, les invite pour le lendemain à un autre banquet dans une vie nouvelle $»^{38}$. Il prend également Sparte pour exemple, quand il expose ses idées en matière pénale, spécialement dans ses premiers discours dans lesquels il s'opposait alors à la peine de mort avec une grande conviction : "La plus terrible de toutes les peines pour l'homme social, c'est l'opprobre, c'est l'accablant témoignage de l'exécration publique ${ }^{30}$. La peine capitale était relativement peu prononcée à Sparte. Il est vrai que tout l'apprentissage des citoyens consistant à faire mépriser la mort, elle n'aurait pas eu l'effet punitif escompté. En revanche, la gloire étant la seule distinction permise, la dégradation civique devenait le supplice le plus affligeant. Il renvoie encore à Sparte sur certains sujets ponctuels, comme lorsqu'il a vainement tenté de s'opposer aux velléités guerrières attisées par l'exécutif et soutenues par une majorité de députés : "La guerre perdit la liberté de Sparte, dès qu'elle porta ses armes loin de ses frontières. La guerre habilement provoquée et dirigée par un gouvernement perfide, fut l'écueil le plus ordinaire de tous les peuples libres ${ }^{40}$.

(36) Ibid., Tome V, Les journaux, Letrres à ses commettants, édition critique préparée par Gustave LAURENT, Imprimeric Louis-Jean, Gap, 1962, "Observations générales sur le projet d'instruction publique proposé à la Convention Nationale (10 janvier 1793) », p. 210.

(37) Ibid., Tome X, Séance du 7 prairial an II (26 mai 1794), « Sur les crimes des rois coalisés contre la France », p. 476 : "Ce qui constituc la république, ce n'est ni la pompe des dénominations, ni la victoire, ni la richesse, ni l'enthousiasme passager, c'est la sagesse des lois, et surtout la bonté des moeurs ; c'est la pureté et la stabilité des maximes de gouvernement. Les lois sont à faire, les maximes du gouvernement à assurer, les mueurs à régénérer ».

(38) Ibid., Séance du 18 floréal an II (7 mai 1794), p. 453 et 454.

(39) Ihid., Tome VII, Séance du 30 mai 1791, "Sur la peine de mort », p. 435 et 436 : « La force des lois dépend de l'amour et du respect qu'elles inspirent et cet amour, ce respect dépendent du sentiment intime qu'elles sont justes et raisonnables. Ouvrez l'histoire de tous les peuples : vous verrez que la douceur des lois pénales y est toujours en raison de la liberté, de la sagesse, de la douceur du gouvernement ".

(40) Ibid.. Tome VIII, Séance du 18 décembre 1791, « Sur le parti que l'Assemblée Nationale doit prendre relativement à la proposition de guerre, annoncée par le pouvoir exécutif ", p. 49,60 et 61 . 


\section{Le dépassement de la référence antique}

Très vite, sous la Convention, Sparte apparaît déjà comme dépassée dans la quête de la fameuse vertu. Robespierre s'émancipe même des grands philosophes de ce siècle. Il écarte ainsi le schéma fixé par Montesquieu et parvient à marier deux notions qui semblaient jusqu'alors incompatibles, la terreur et la vertu : «Si le ressort du gouvernement populaire dans la paix est la vertu, le ressort du gouvernement populaire en révolution est à la fois la vertu et la terreur : la vertu, sans laquelle la terreur est funeste ; la terreur, sans laquelle la vertu est impuissante. La terreur n'est autre chose que la justice prompte, sévère, inflexible; elle est donc une émanation de la vertu; elle est moins un principe particulier, qu'une conséquence du principe général de la démocratie, appliqué aux plus pressants besoins de la patrie ${ }^{41}$. La théorie de Robespierre met en relief la fragilité du régime démocratique : la simple invocation du peuple peut à tout moment le faire basculer dans le despotisme. Le raisonnement de Robespierre tendant à faire de la terreur une émanation de la vertu en temps de crise est très audacieux. Il y aurait donc une terreur « juste » issue de la démocratie et une terreur "partiale », celle exercée par une autorité despotique $^{42}$. Ici Robespierre flirte plus avec Machiavel qu'avec les penseurs de son siècle. Les Spartiates eux-mêmes n'ont jamais imaginé que la terreur pouvait inciter à la vertu. Leurs règlements sévères et leurs pratiques parfois cruelles ne relèvent pas du même esprit que la justice expéditive du Comité de Salut public et de ses tribunaux révolutionnaires. Robespierre ne voit pas que l'exercice de la terreur l'éloigne de la tâche qu'il s'est assignée.

Le signe de ce dépassement de Sparte se perçoit dans la mission sacrée qu'il confie à la France républicaine : «Seul, entre tous les peuples du monde, il [le peuple français] est fait pour rétablir sur la terre le règne de la liberté. Seul il joint les vertus douces aux vertus énergiques, et la modération des peuples éclairés, à la vigueur des peuples libres. [...] II respecte les lois : il abat les tyrans [...] il foudroie les despotes du monde et dissipe devant lui, leurs satellites comme la poussière ${ }^{43}$. Il est vrai que cet article prend plus la forme d'une harangue que d'un véritable projet politique, mais Robespierre n'en est pas moins convaincu du rôle unique et

(41) M. de RobeSPIERre, Euvres complètes, op. cit., Tome X. Séance du 17 pluviôse an II (5 fév. 1794), p. 357

(42) Cette démarche tendant à définir des étapes incontournables pour aboutir à un ordre définitif qui assurera le bonheur commun sera reprise dans les siècles à venir, notamment dans la pensée communiste où l'on parle d'une nécessaire période de dictature du prolétariat avant d'atteindre l'état d'égalité absolu.

(43) M. de RobespierRe, Euvres complètes, op. cit., Tome V, Article du 30 janvier 1793 (Nº), p. 245. 
universel du peuple français. Au cours du $\mathrm{VI}^{c}$ siècle avant notre ère, les Spartiates avaient chassé les tyrans d'un certain nombre de cités, puis, à la tête des Grecs, ils ont lutté contre l'envahisseur perse, enfin ils se sont érigés face à l'impérialisme athénien. Ils ont été à leur échelle les défenseurs de la liberté de l'Hellade, la France doit reprendre le flambeau dans un monde bien plus vaste et bien plus complexe : "Une nation n'est pas illustre pour avoir abattu des tyrans ou enchaîné des peuples ; ce fut le sort des Romains et de quelques autres nations : notre destinée beaucoup plus sublime est de fonder sur la terre l'empire de la sagesse, de la justice et de la vertu ${ }^{44}$. Face aux exemples antiques, Robespierre affirme donc le caractère sui generis de la république française. Elle est bien plus avancée que ses anciennes socurs dans le caractère démocratique de ses institutions. Sa capacité à dépasser le cadre de la citć justifie l'ampleur de son ambition et de son rayonnement.

En tant que grand inspirateur du Comité de Salut public, Robespierre va essayer d'intégrer dans son programme politique, au-delà de la terreur élevée au rang de principe, quelques réalisations dont on peut soupçonner une origine spartiate.

\section{Les visées « spartiates » de Robespierre}

Au sein du système spartiate issu de la législation de Lycurgue, on peut puiser à l'infini des éléments en appui de bon nombre de théories politiques. Ce que Robespierre retient essentiellement dans cette œuvre, c'est la cohésion de la société et du corps politique. Il va s'employer sans relâche à atteindre lui aussi ce résultat.

\section{L'amour de la patrie}

Robespierre confère aux vertus martiales un rôle essentiel, surtout dans le contexte de périls intérieurs et extérieurs. Comme Lycurgue, il voudrait extirper de l'homme toutes ses faiblesses. Le service de la patrie n'admet pas la peur, aussi, dans un discours sur le siège de Valenciennes, il accable Briez, qu'il accuse d'avoir abandonné ses troupes : "Si j'avais été à Valenciennes dans cette circonstance, je n'aurais jamais été dans le cas de vous faire un rapport sur les événements du siège, $\mathrm{j}$ 'aurais voulu partager le sort des braves défenseurs qui ont préféré une mort honorable à une honteuse capitulation $»^{45}$. À cette attitude, il peut opposer l'exemple de

(44) Ihid., Tome X, Séance du 21 messidor an II (9 juillet 1794), p. 521.

(45) Ibid., Séance du 25 septembre 1793, "Pour le Comité de Salut Public et contre Briez ", p. 121. 
Joseph Bara, jeune tambour capturé et tué par les Chouans en 1793 pour avoir refusé de renier la république ${ }^{40}$, dont il se sert pour remuer les cœurs et attiser l'émulation et le courage inspiré par le patriotisme et l'attachement aux lois et aux valeurs du régime. La place qu'il voudrait lui accorder au Panthéon témoigne bien de ce désir de voir renaitre le culte des héros : "Il n'est pas possible de choisir un plus bel exemple, un plus parfait modèle pour exciter dans les jeunes cœurs l'amour de la gloire, de la patrie et de la vertu, et pour préparer les prodiges qu'opérera la génération naissante. En décernant des honneurs au jeune Bara, vous les décernez à toutes les vertus [...] Les Français seuls ont des héros de treize ans, c'est la liberté qui produit des hommes d'un si grand caractère. Vous devez présenter ce modèle de magnanimité, de morale à tous les Français et à tous les peuples : aux Français, afin qu'ils ambitionnent d'acquérir de semblables vertus [...] aux autres peuples, afin qu'ils désespèrent de soumettre un peuple qui compte des héros dans un âge si tendre $»^{47}$. En effet, quel étendard pour la jeunesse française ! Une telle constance serait digne des faits les plus admirables ou les plus étranges rapportés par Plutarque au sujet des enfants de Sparte. Seul l'amour de la patrie peut faire mépriser à ce point la mort. Nourris par des valeurs républicaines les citoyens deviendront, tout comme les Lacédémoniens, les meilleurs remparts de l'État.

Pourtant, Robespierre ne souhaite pas abandonner l'amour de la patrie au seul domaine militaire. Il va donc reprendre ce qui avait été imaginé dans l'Antiquité pour maintenir la cohésion sociale et le sentiment d'appartenance à une même nation, à savoir les fêtes civiques ${ }^{48}$. Il semble admirer la sagesse des législateurs anciens, Lycurgue en tête, pour avoir parfaitement analysé l'enthousiasme et l'énergie commune qui peuvent se dégager de tels rassemblements, qu'il ne restera plus qu'à orienter en faveur de l'État : « Il est cependant une sorte d'institution qui doit être considérée comme une partie essentielle de l'éducation publique, et qui appartient nécessairement au sujet de ce rapport. Je veux parler des fêtes

(46) Ibid., Séance du 8 nivôse an II (28 déc. 1793), " Pour que les honneurs du Panthéon soient décernés au jeune Bara ", p. 293 : “ Entouré de brigands qui d'un cóté, fui présentaient la mort, et de l'autre lui demandaient de crier vive le roi ! Il est mort en criant vive la République ! ".

(47) Ibid.

(48) Sur ce thème, on peut se référer à quelques travaux : J. Duvignaud, La fête civique, Histoire des spectacles, Paris, Gallimard, 1965 ; J. Ehrard et $P$. V LALANFIX (dir.), Les fêtes de la Révolution, Colloque de Clermont-Ferrand, juin 1974, Bibliothèque d'Histoire Révolutionnaire, Société des Études Robespierristes, $3^{c}$ série, $n^{\circ} 17$; F. LAIDle, " Parents, enfants, la famille dans la fête révolutionnaire. Image et symbole d'unc régénération juridique », dans Parents et enfants, Colloque International tenu à Dijon les 14, 15 et 16 sept. 2000, Mémoire de la Société pour l'Histoire du Droit, Vol. 58, 2001, p. 493-510, et "Comment former les citoyens sous la Révolution française? Ou la régénération et la fête révolutionnaire ", dans Sujets et citoyens, Actes du Colloque de Lyon tenu en sept. 2003, Coll. Histoire des Idćes Politiques, Presses Universitaires d'Aix-Marseille, Aix-en-Provence, 2004, p. 269-277; M. OzoUf, La fête révolutionnaire 1789. 1799, Paris, Gallimard, 1988 ; et Michel VOVEt.le, "Sociologie ou idéologie des fêtes de la Révolution ", $A H R F, 221,1975$, p. 429. 
nationales. Rassemblez les hommes, vous les rendrez meilleurs ; car les hommes rassemblés chercheront à se plaire, et ils ne pourront se plaire que par les choses qui les rendent estimables. Donnez à leur réunion un grand motif moral et politique [...] On ne parle jamais sans enthousiasme des fêtes nationales de la Grèce [...] on voyait un spectacle plus grand que les jeux, c'étaient les spectateurs eux-mêmes ; c'était le peuple vainqueur de l'Asie, que les vertus républicaines avaient élevé quelquefois au-dessus de l'humanité [...] Combien il serait facile au peuple français de donner à ses assemblées un objet plus étendu et un plus grand caractère! Un système de fêtes nationales bien entendu, serait à la fois le plus doux lien de fraternité et le plus puissant moyen de régénération ${ }^{49}$. Les Grecs étaient parvenus à cette communion si chère à Robespierre. Ces fêtes célébraient à la fois la liberté, l'amour de la patrie et le respect des lois ${ }^{50}$. La France doit toutefois se distinguer, aller plus loin, aussi « l'incorruptible » y ajoute l'égalité, le peuple et, enfin, l'humanitési. Les objectifs d'un État plus étendu et d'une nation plus nombreuse sont nécessairement plus ambitieux. Robespierre demeure dans cette optique de mission universelle du peuple français.

Les fêtes révolutionnaires souhaitées par Robespierre reflètent celles données à Lacédémone en requérant la participation de tous : « Vous y serez, braves défenseurs de la patrie, que décorent de glorieuses cicatrices. Vous y serez, vénérables vieillards, que le bonheur préparé à votre postérité doit consoler d'une longue vie passée sous le despotisme. Vous y serez, tendres élèves de la patrie, qui croissez pour étendre sa gloire et pour recueillir le fruit de nos travaux $»^{52}$. On sait, grâce aux anciens, que lors des fêtes spartiates, qu'il s'agisse des Carnéia, des Hyacinthies ou des Gymnopédies $^{\text {sis }}$, les hommes défilaient par ordre de génération, les vieillards en tête, ensuite les hommes faits, et enfin les jcunes gens, tout en entonnant des chants propres à leur état. Robespierre estime lui aussi que les anciens ont un immense rôle fédérateur, ils sont l'image vivante de la pérennité et du respect des lois. Tout comme à Sparte, la participation du sexe féminin revêt un caractère primordial : « Vous y serez, jeunes citoyennes, à qui la victoire doit ramener bientôt des frères et des amants dignes

(49) M. de RobespiERre, Euvres complètes, op. cit., Tome X, Séance du 18 floréal an II (7 mai 1794), p. 458 et 459.

(50) Ibid., p. 459 ; “ Que toutes [les fêtes nationales] tendent à réveiller les sentiments généreux qui font le charme et l'ornement de la vie humaine, l'enthousiasme de la liberté, l'amour de la patrie, le respect des lois $m$.

(51) Ibid., Tome VIII, Séance du 10 février 1792, "Sur les moyens de maintenir l'ordrc ", p. 179 : " Je n'ai ici en vue que quelques mesures simples et grandes, pour propager rapidement l'esprit public et les principes de la Révolution, au nombre desquelles je mettrais les fêtes nationales. [...] Pourvu que le génie de la liberté les ordonnât, et que l'égalité, le peuple et l'humanité, fussent les scules divinités honorées des hommages des citoyens ".

(52) Ibid., Tome X, Séance du 18 Floréal an Il (7 mai 1794), p. 461.

(53) Il s'agit de fêtes ayant lieu l'été et durant chacune une huitaine de jours. 
de vous. Vous y serez, mères de famille, dont les époux et les fils élèvent des trophées à la république avec des débris de trônes. Ô femmes françaises, chérissez la liberté achetée au prix de leur sang ; servez-vous de votre empire pour étendre celui de la vertu républicaine ! [...] Qu'avez-vous à envier aux femmes de Sparte ? Comme elles, vous avez donné le jour à des héros ; comme elles, vous les avez dévoués, avec un abandon sublime, à la patrie $\aleph^{s 4}$. Robespierre fait des filles et des femmes les inspiratrices et les gardiennes des vertus républicaines. Le peuple français tout entier doit être uni. Les fêtes constituent des points d'ancrage indispensables afin d'inculquer un sentiment de commune destinée.

Robespierre dévoile ce qui pourrait constituer le contenu de ces événements : « Ne pouvez-vous pas du moins, comme chargés de maintenir la liberté et les mœurs, ordonner qu'à certains jours, les chefs-d'œuvres dramatiques qui peignent les charmes de la vertu et les prodiges de la liberté, tels que Brutus, Guillaume Tell, Gracchus, seront joués de temps en temps au profit des victimes du despotisme ? [...] Si nous voulons imiter, que n'imitons-nous pas ces institutions sublimes des peuples de la Grèce, ces jeux solennels où les artistes et les poètes, les orateurs qui avaient illustré leur pays et enflammé les cours de leurs concitoyens du feu sacré de la vertu et de la liberté, recevaient à la face du plus magnanime de tous les peuples, le prix de leurs talents et de leurs services $"^{55}$. Une fois encore, il met en exergue la vertu de l'exemple. S'il affirme par ailleurs ne pas vouloir imiter les Grecs, il situe néanmoins la république française dans leur lignée. La proportion des peuples et des tâches à accomplir diffèrent mais l'inspiration demeure identique.

La fête de «L'Être suprême » est une illustration de cette copie de célébration antique, mais elle s'est trouvée en complet décalage avec les sentiments du public. Il faut dire que cette bizarrerie joyeuse trônant sur une politique de terreur avait de quoi inquiéter les citoyens. On a pu ainsi mesurer la distance entre les volontés des dirigeants et les aspirations du peuple.

Robespierre opère pourtant un tri parmi les institutions antiques destinées à souder les citoyens autour du bien commun. Ainsi, il rejette l'idée des repas républicains, les Syssities ou Phidities spartiates ${ }^{56}$. La méfiance prend ici le dessus sur sa volonté unificatrice. Il ne perçoit dans

(54) M. de Robespierre, Cuures complètes, op. cit., Tome X, Séance du 18 floréal an II (7 mai 1794), p. 461 .

(55) Ibid., Tome VIII, Séance du 10 février 1792, p. 179 et 180.

(56) Il s'agit des repas des citoyens pris publiquement, où chacun participe en apportant un écot prédéfini issu du domaine dont il a l'usufruit. 
ces institutions que des repères de comploteurs ${ }^{57}$. La fameuse phobie des factions altère son projet de cohésion nationale. Robespierre se pose en grand ordonnateur de la république. Il voudrait avoir l'œil sur toutes les institutions qui se créent. C'est lui qui doit orienter l'idée républicaine et définir le patriotisme. Il ne supporte pas que se développent des manifestations parallèles échappant à l'emprise étatique. Ici, parce que cela lui est commode, il se permet de prévenir ses compatriotes contre la manie antiquisante et plus précisément l'exemple spartiate : « Je pourrais vous étaler des descriptions brillantes de fêtes nationales, et produire peut-être un moment d'illusion, en vous présentant le fantôme de quelques institutions lacédémoniennes, étrangères à notre situation actuelle ; mais avant de s'occuper des détails il faut combiner le plan, et surtout établir les principes ; avant d'instituer le peuple, il faut le conserver et le constituer ${ }^{58}$. Cela démontre également que Robespierre ne se situe pas dans une imitation fanatique du modèle spartiate. Il tient compte des différences de contexte.

Cependant, il n'a pas renoncé à réformer les mœurs des Français comme le fit Lycurgue en son temps, et le plan d'éducation qu'il soutient paraît en étroite symbiose avec les vues du législateur lacédémonien.

\section{La reprise du plan d'éducation nationale de Michel Lepeletier}

Robespierre a bien compris que l'esprit de la Révolution ne peut se maintenir que si on l'insuffle aux générations en devenir. La Révolution ne doit pas être un simple événement, une révolte, elle doit s'inscrire dans la durée. Elle doit marquer la naissance d'un homme nouveau ${ }^{59}$. À cet effet l'éducation prend une importance considérable. Certes le débat sur cette matière avait débuté quelques décennies plus tôt, quand le pouvoir royal s'est décidé à mettre fin au rôle majeur des Jésuites. Une première vague de projets tendant à étatiser l'institution s'était alors développée avec des

(57) M. de Robespierre, CEures complètes, op. cit., Tome X, Séance du 28 messidor an II (I6 juillet 1794), p. 534 : " Le succès momentané des prétendus banquets patriotiques a eu sa source dans le sentiment général de civisme qui anime le peuple entier. Les premièrcs tentatives sont venues de la perversité des intrigants qui ont des vues perfides, telles que celle d'amollir l'opinion publique, et d'endormir les amis de la liberté ".

(58) lbid., Tome V, Séance du 10 janvier 1793, « Observations générales sur le projet d'instruction publique proposé à la Convention Nationale ", p. 211.

(59) lhid., Tome IX, Séance du 25 juin 1793, « Pour que la convention s'occupe des grands intérêts de la Nation ", p. 595 : " Faites des lois populaires; posez les bases de l'instruction publique, régénérez l'esprit public, épurez les moeurs, si vous ne voulez perpétuer la crise de la Révolution ». 


\section{effets très limités ${ }^{(x)}$. La Révolution, fondée sur de nouvelles valeurs et sur des principes différents de ceux de la monarchie, a redonné vigueur à l'ef- fort de réforme ${ }^{6 !}$. Ainsi, le 12 octobre 1789, la Constituante lance un appel solennel à tous ceux qui ont des vues sur ce sujet afin qu'ils les exposent.}

(60) Sur la question de l'éducation au XVIII' siècle voir : E. BecCHI et D. JuLIA, Histoire de l'enfance en Occident, Tome II, Du XVIII siècle à nos jours, Seuil, Paris, 1998 ; Serge Bonin, Claude Langlois et D. Jul1a (dir.), Atlas de la Révolution française : L'enseignement (1760)-1815), Paris, éd. de l'École des Hautes Études en Sciences Sociales, 1987 ; R. Chartier, M.M. Complere et D. JuLiA, L'éducation en France du XVT au XVIII, siècle, Paris, 1976 ; G. CompaYre, Histoire critique des doctrines de léducation en France depuis le XVT siècle, 2 vol., Paris, 1879 ; Fr. de La FonTAINERIE, French liberalism and education in the 18 th century : the writings of La Chalotais, Turgot, Diderot and Condorcet on national education, New-York, 1932 ; G. Mialaret et J. Vial, Histoire' mondiale de l'éducation de 1515 à 1815 , Paris, 1981 ; D. SchaARYSCHEUERMANN, "Education nationale " et "Instruction publique " dans les mouvements des idées en France dans la seconde moitié du XVII' siècle, Paris, Thèse, Sorbonnc, 1958 ; A. SiCARD, L'éducation morale et civique avant et pendant la Révolution, 1700-1808, Paris, 1884 ; G. SNYDERS, La pédagogie en France aux XVII et XVIII siècles, Paris, PUF, 1965 ; et J. de VIGUERIE, $L$ institution des enfants. L'éducation en France alx XVII et XVIII siècles, Paris, 1978. Parmi les projets développés, on peut en citer quelques-uns : François TURBEN, Idées d'un citoyen sur l'instruction de la jeunesse ou projet d'éducation générale et particulière, Paris, 1761 ; DARAGON, Lettre de $M^{* * *}$ à l'abbé ${ }^{* * *}$ sur la nécessité et la manière de faire entrer un cours de morale dans l'éducation publique, 1762 ; Соцомв, Plan raisonné d'éducation publique pour ce qui regarde la partie des études, Avignon, Paris, 1762 ; Louis René de Caradeuc de La Culalotals, Essai d'éducation nationale, ou plan d'études pour la jeunesse, s. 1., 1763 (repris dans la revue Dix-huitième Siècle, présenté et annoté par Robert Grandroute, 1996); Louis Bernard GUYTON DE MORVEAU, Mémoire sur l'éducation publique, avec le prospectus d'un collège suivant les principes de cet ouvrage, s. l., 1764 ; Méthode d'éducation nationale par $R^{* * *}$ $T^{* * *}, 1765$; Jean Jacques Garnier, De l'éducation civile, Paris, 1765 ; Gabriel François CoYEk, Plan d'éducation publique, Paris, 1770 ; François SАВВАТІІк, Les moeurs, coutumes et usages des anciens peuples, pour senvir à l'éducation de la jeunesse. Chảlons, 1770; du méme auteur, Les exercices $d u$ corps chez les anciens, pour servir à l'éducation de la jeunesse, 2 vol., Paris, 1772 ; M.-J.-A.-N.C., M. de CondorCET, Mémoire inédit sur l'éducation, rédigé en 1774 (dans L. Gutro, Libenà degli antichi e libenà dei modemi, Sparta, Atene e $i$ "philosophes " nella Francia del Settecento, Naples, Guida, 1979, p. 219 et 220); MtrCIER DE LA RivierE, De l'instruction publique ou considérations morales et politiques sur la nécessité, la nature et les sources de cette instruction, Paris, 1775 ; RollAnd d'ERCEvILLE, Compte-rendu aux Chambres assemblées des différents mémoires envoyés par les universités... relativement au plan d'études à suivre dans les collèges non dépendants des universités, et à la comespondance à établir entre les collèges et les universités, Recueil de plusicurs ouvrages de M. Le Président Rolland, Paris, 1783 ; Lićvin-Bonaventure ProyarT, De léducation publique et des moyens d'en réaliser les réformes projetées dans la demière Assemblée générale du Clergé en France, Paris, 1785 ; ou Jean Joseph MouniER, Plan d'éducation nationale adressé aux États-Généraux par un père de famille dauphinois, s. 1., 1789

(61) Il existe de nombreux ouvrages sur la question de l'éducation sous la période révolutionnaire : B. BaCzko, Une éducation pour la démocratie. Textes et projets de l'époque révolutionnaire, Paris, Garnier, 1982, et "Instruction publique ", dans F. FURET et M. OzOUF (dir.), Dictionnaire critique de la Révolution française, Paris, Flammarion, 1992, p. 279 ; A. de BAECove, "La Révolution accueille la Régénération. Naissance, éducation et prétention du nouvel homme ", dans La Révolution française et lhomme moderne, Colloque International de Rouen tenu les 12, 13 et 14 oct. 1988, IRED Université de Rouen. Paris, Messidor, 1988, p. 667 ; C. Coutel, La République et l'école, une anthologie, Paris, Presses Pockets, 1991 ; M. Ozouf, "Régénération ", dans F. FURI: et M. Ozouf, Dictionnaire critique de la Révolution française, op. cit., p. 380 ; D. Julıa, La Révolution : les trois couleurs du tableau noir, Paris, Belin, 1981, et "Léducation révolutionnaire, fille de Sparte ou héritière des Lumières ", dans P. LENoFt. et M.-F. LEVY (dir.), L'enfant, la famille, la Révolution française, Colloque tenu à Paris-Sorbonne, les 30,31 janv. et $\mathrm{I}^{\text {er }}$ fév. 1989, Paris, Orban, 1989, p. 121 et s. ; B. LEHEMBRE, Naissance de l'école moderne. Les lextes fondamentaux 1791-1804, Paris, Nathan, 1989 ; C. MORIN-FAVROT, L'instruction publique dans la pensée révolutionnaire, 1789-1795, Mémoire pour le DEA D'Histoire des Institutions et des Idées Politiques sous la direction de Michel Ganzin (dact.), Faculté de Droit et de Science Politique, Université Aix-Marseille III, 1996 ; M. Ozouf, Essai sur la Révolution, l'utopie el l'enseignement, Paris, 1984 ; et F. PonTEIL, Histoire de l'enseignement : 1789-1965, Paris, Sirey, 1966. Il ne faut pas oublier la compilation essentielle de J. GuILLAUME, Procès-verbaux du Comité d'Instruction Publique de la Convention Nationale, Documents inédits pour l'Histoire de France, Imprimerie Nationale, Paris, 1891. 
Ils affluent jusque sous la Convention. L'engouement pour l'Antiquité aidant, nombre de plans se réfèrent à la fameuse éducation spartiate ${ }^{\natural 2}$. Parmi ceux-ci, il y en a un qui retient plus spécialement l'attention de Robespierre, celui de Michel Lepeletier de Saint-Fargeau, au point qu'il le présente lui-même à l'Assemblée, son auteur ayant été assassiné, et c'est à partir de ce projet qu'il va faire des propositions concrètes.

Dans l'optique d'une régénération de l'homme, la constitution de mœurs en adéquation avec le régime politique apparaît comme une priorité. Laccent sera donc mis sur la formation morale : "Quelles sont les choses qu'il importe surtout d'apprendre aux citoyens ? Ce sont les droits de l'humanité ; ce sont les devoirs de chaque homme envers son semblable ; ce sont les principes divins de la morale et de l'égalité ${ }^{\text {hi3 }}$. En second lieu, toujours dans la même démarche, il faut s'attaquer à la formation du citoyen : « Il ne s'agit plus de former des “ messieurs " mais des citoyens ". $^{\text {. }}$. L'éducation organisée par l'État semble donc être le socle le plus approprié à de telles vues : "La patrie a seule le droit d'élever ses enfants ; elle ne peut confier ce dépôt à l'orgueil des familles, ni aux préjugés des particuliers, aliments éternels de l'aristocratie et d'un fédéralisme domestique, qui rétrécit les âmes en les isolant, et détruit, avec l'égalité, tous les fondements de l'ordre social $\aleph^{65}$. Robespierre établit ainsi une corrélation indéfectible entre éducation nationale et démocratie.

Le caractère étatique, national, est encore accentué par Lepeletier qui ajoute que cette éducation devra être obligatoire ${ }^{6 /}$. Cela rejoint la logique du projet de Robespierre, la régénération de l'homme. La latitude ou la négligence en ce domaine annihilerait tous les effets voulus. Aussi Robespierre retranscrit cette proposition dans un article III du projet de décret qu'il présente à l'Assembléc le 29 juillet 1793 : « Léducation natio-

(62) Archives Parlemenaires, Tome LV, Séance du 18 décembre 1792, Ducos, p. 141, Leclerc, p. 142-144, Tome LX, Séance du 21 décembre 1792, Rabaut Saint-Étienne, p. 346, Tome LXIX, Séance du 29 juillet 1793, Léonard Bourdon, "Projet de décret sur l'éducation nationale ", p. 679-685, Tome LXVIII, Séance du 3 juillet 1793, A. H. Wandelaincourt, "Plan d'éducation publique ", p. 227, Tome LXVIII, Séance du 3 juillet 1793, Alexandre Deleyre, "Idées sur l'éducation nationale ", p. 179-194, Tome LXIX, Séance du 29 juillet 1793, Charles Delacroix, “ Projet de loi sur l'éducation commune ", p. 670-675. Il ne faut pas oublier le projet de Lakanal de juin 1793 repris dans J. Gros, Lakanal et l'éducation nationale, Paris, Andrć Fils, 1912, ct évoqué par D. Julia, La Révolution : les trois couleurs du tableau noir, op. cit., p. 331 .

(63) M. de Robespierre, Euvres completes, op. cit., Tome V, Séance du 10 janvier 1793, "Observations générales sur le projet d'instruction publique, proposé à la Convention Nationale ", p. 209.

(64) lidid., Tome X, Séance du 18 floréal an Il (7 mai 1794), p. 458.

(65) $\mathrm{lbid}$.

(66) Ibid., "Sur le plan d'ćducation nationale de Michel Lepeletier" (29 juillet 1793), p. 11 et 18 : "Linstitution publique des enfants sera-t-elle d'obligation pour les parents, ou les parents auront-ils seule. ment la faculté de profiter de ce bienfait national ? D'après les principes, tous doivent y être obligés. Pour l'intérét public, tous doivent y être obligés [...] Lepeletier voulait que l'éducation nationale fût forcée, c'està-dire, que tous les pères fussent contraints de faire élever leurs enfants en commun dans les écoles publiques ». 
nale étant la dette de la République envers tous, tous les enfants ont droit de la recevoir, et les parents ne pourront se soustraire à l'obligation de les faire jouir de ses avantages $»^{67}$.

Même s'il n'était pas le premier à le faire, Lepeletier avait perçu une différence fondamentale entre deux notions : l'éducation et l'instruction. Il juge qu'on ne s'est jusque-là occupé que de la seconde, c'est-à-dire le développement et l'exploitation des aptitudes de chacun à exercer tel ou tel métier ou à occuper certaines fonctions. Léducation, elle, a une finalité plus universelle, elle touche tous les enfants quelle que soit leur condition. Elle est non seulement le socle des connaissances élémentaires, mais elle doit aussi insuffler l'esprit de la nation dans la jeunesse du pays. Cet aspect, qui n'a pas été envisagé dans un cadre national, a, par conséquent, fait l'objet de peu de soin"is. Il faut donc redonner à "l'éducation » sa primauté naturelle. Lepeletier s'est donc essentiellement intéressé aux règles et aux institutions ayant trait à l'enfance encore tendre, à l'âge où les esprits sont les plus disposés à recevoir les principes de la république et de la vie en société. À l'inverse de Lycurgue, il n'escompte pas poursuivre cette expérience au-delà, car les Français sont déjà imprégnés de certaines habitudes qu'il ne serait pas raisonnable de vouloir expurger : "Prolonger l'institution publique jusqu'à la fin de l'adolescence est un beau songe ; quelquefois nous l'avons rêvé délicieusement avec Platon ; quelquefois nous l'avons lu avec enthousiasme dans les fastes de Lacédémone : quelquefois nous en avons retrouvé l'insipide caricature dans nos collèges; mais Platon ne faisait que des philosophes, Lycurgue ne faisait que des soldats, nos professeurs ne faisaient que des écoliers ; la République française, dont la splendeur consiste dans le commerce et l'agriculture, a besoin de faire des hommes de tous les états ${ }^{\$ 9}$. Les Spartiates n'étaient que des guerriers, les Français, conformément aux souhaits de Rousseau ou de Mably, aspirent à développer une vertu plus complète. Les principes démocratiques et les

(67) Ibid., «Projet de décret sur l'éducation nationale, par le citoyen Robespierre " (29 juillet 1793), p. 35.

(68) Ibid., "Sur le plan d'éducation de Michel Lepeletier ", p. 12 et 13 : "J'avoue pourtant que ce qui a été dit jusqu'ici ne remplit pas l'idée que je me suis formé d'un plan complet d'éducation. J'ai osé concevoir une plus vaste pensée ; et considérant à quel point l'espèce humaine est dégradée par le vice de notre ancien système social, je me suis convaincu de la nécessité d'opérer une entière régénération et, si je peux m'exprimer ainsi, de créer un nouveau peuple. Former des hommes, propager les connaissances humaines ; telles sont les deux parties du problème que nous avons à résoudre. Lit première constitue l'éducation ; la seconde, l'instruction. Celle-ci, quoique offerte à tous, devient par la nature méme des choses, la propriété exclusive d'un petit nombre de membres de la société, à raison de la différence des professions et des talents ; Celle-là doit être commune à tous et universellement bienfaisante. Quant à l'une, le comité s'en est occupé et il vous a présenté des vucs utiles. Pour l'autre ii l'a entièrement négligée. En un mot, son plan d'instruction publique me paraît fort satisfaisant ; mais il n'a point traité l'éducation [...] Mais avant ces degrés supérieurs qui ne peuvent devenir utiles qu’à un petit nombre d’hommes, je cherche une instruction générale pour tous, convenable aux besoins de tous, qui est la dette de la République envers tous ; en un mot, une éducation vraiment et universellement nationale $n$.

(69) lbid., p. 17. 
progrès techniques rendent indispensable l'exercice d'arts et de talents dans bien d'autres domaines.

Cependant, Lepeletier rejoint Lycurgue dans ses objectifs, notamment la formation d'un peuple nouvcau". Dans cette opération de "mutation ", le vocabulaire employé par Lepeletier est assez remarquable. À de nombreuses reprises il utilise des expressions tirées du monde de l'industrie, comme « matière première " ou " moule ", afin de montrer ce que l'on peut obtenir d'esprits malléables : " Dans l'institution publique au contraire, la totalité de l'existence de l'enfant nous appartient ; la matière, si je peux m'exprimer ainsi, ne sort jamais du moule ; aucun objet extérieur ne vient déformer la modification que vous lui donnez " ". L'éducation n'est pas autre chose que la « confection » de citoyens.

Lepeletier et Robespierre veulent atteindre un certain degré d'égalité. Il faut pour cela former la jeunesse à la discipline et à l'obéissance aux lois de la République : "Ployés tous les jours et à tous les instants sous le joug d'une règle exacte, les élèves de la patrie se trouveront tous formés à la sainte dépendance des lois et des autorités légitimes ${ }^{72}$. Cette discipline s'apparente à celle qu'on rencontre dans l'institution militaire, dont Lepeletier admire les vertus : "Voyez ce jeune soldat avant qu'il ne s'engage et retrouvez-le après qu'il a servi quelques temps ; ce n'est plus le même homme $[. .$.$] Combien ce moyen ne sera-t-il pas plus efficace, étant$ dirigé sur les organes souples et flexibles de l'enfance, modifié avec philosophie et mis en œuvre avec habileté et intelligence ${ }^{73}$. L'éducation dans la jeune république, tout comme à Sparte, sera donc toujours en étroite liaison avec les valeurs martiales.

Cela influe considérablement sur la forme et le contenu de l'enseignement. Léducation doit tout d'abord être égalitaire. À ce titre elle sera dispensée autant aux garçons qu'aux filles dans la tranche d'âge la plus

(70) Ibid., p. 15 et 32 : “Cette loi consiste à fonder unc éducation vraiment nationale, vraiment républicaine, également et efficacement commune à tous, la seule capable de régénérer l'espèce humaine, soit pour les dons physiques, soit pour le caractère moral ; en un mot, cette loi est l'établissement de l'institution publique [...] Ainsi se formera une race renouvelée, forte, laborieuse, réglée, disciplinée, et qu'une barrière impénétrable aura séparée du contact impur des préjugés de notre espèce vieillie ".

(71) Ibid., p. 19, 24 et 32 : "N'oublions pas quel est l'objet de cette première éducation commune à tous, égale pour tous. Nous vouions donner aux enfants les aptitudes physiques et morales, qu'il importe à tous de retrouver dans le cours de la vie, quelle que soit la position particulière de chacun. Nous ne les formons pas pour telle ou telle destination déterminée, il faut les douer des avantages dont l'utilité est commune à l'homme dans tous les états ; en un mot, nous préparons, pour ainsi parler, une matière première, que nous tendons à rendre essenticllement bonne, dont nous élaborons les éléments de telle sorte, qu'en sortant de nos mains, elle puisse recevoir la modification spéciale des diverses professions dont se compose la République. [...] Ainsi, depuis cinq ans jusqu'à douze, c'est-ä-dirc dans cette portion de la vie si décisive pour donner à l'être physique el moral la modification, l'impression, l'habitude qu'il conservera toujours, tout ce qui doit composer la République, scra jeté dans le moule républicain ».

(72) lbid., p. 21 et 22 : "Je n'attache pas un moindre prix à l'habitude d'une austère discipline. Souvenons-nous que nous élevons des hommes destinés à jouir de la liberté, et qu'il n'existe pas de liberté sans obéissance aux lois ".

(73) Ibid., p. 22. 
propice, à ses yeux, pour inculquer les principes républicains, et, subsidiairement, détecter les talents ${ }^{74}:$ « Je demande que vous décrétiez que, depuis l'âge de cinq ans jusqu'à douze pour les garçons et jusqu'à onze pour les filles, tous les enfants, sans distinction et sans exception, seront élevés en commun, aux dépens de la République ; et que tous, sous la sainte loi de l'égalité, recevront mêmes vêtements, même nourriture, même instruction, mêmes soins $"{ }^{75}$. La proposition est intégralement reprise dans les articles I et II du projet de décret de Robespierre ${ }^{76}$.

Léducation doit aussi tendre à la cohésion nationale, elle doit ignorer les différences sociales et unir dans un même élan riches et pauvres : "Osons faire une loi qui aplanisse tous les obstacles [...] une loi toute en faveur du pauvre, puisqu'elle reporte sur lui le superflu de l'opulence, que le riche lui-même doit approuver s'il réfléchit, qu'il doit aimer s'il est sensible ${ }^{77}$. Lepeletier et Robespierre veulent que tous les regards se tournent vers la patrie au détriment des intérêts particuliers, source de divisions ${ }^{78}$. Lidée d'égalité est organisée autour de la nation.

Aussi, concrètement, le plan de Lepeletier apparaît comme une imitation de l'éducation spartiate. Il semble ignorer totalement le cadre familial. Son système vise plus à orienter les comportements qu'à apporter un savoir : "Continuellement sous l'œil et dans la main d'une active surveillance, chaque heure sera marquée pour le sommeil, le repas, le travail, l'exercice, le délassement ; tout le régime de vie sera invariablement réglé ; les épreuves graduelles et successives seront déterminées ; les genres de travaux du corps seront désignés ; les exercices de gymnastique seront indiqués ; un règlement salutaire et uniforme prescrira tous ces détails, et une exécution constante et facile en assurera les bons effets $"$ "79. La vie de

(74) lhid., p. 15-17 : "Cette portion de la vie est vraiment décisive pour la formation de l'être physique et moral de l'homme. Il faut la dévouer tout entière à une surveillance de tuus les jours, de tous les moments. Jusqu'à cinq ans on ne peut qu'abandonner l'enfance aux soins des mères; c'est le voeu, c'est le besoin de la nature : trop de détails, des attentions trop minutieuses sont nécessaires à cet âge ; tout cela appartient à la maternité. [...] À cinq ans, la patrie recevrá donc l'enfant des mains de la nature : à douze ans, elle le rendra à la société. [...] Jusqu'à douze ans l'éducation commune est bonne, parce que jusque-là il s'agit de former, non des laboureurs, non des artisans, non des savants, mais des hommes de toutes les professions. Jusqu'à douze ans l'ćducation commune est bonne, parce qu'il s'agit de donner aux enfants les qualités physiques et morales, les habitudes et les connaissances qui, pour tous, ont une commune utilité ".

(75) $\mathrm{lbid}$, p. 15 et 32 : "Là traités tous également, nourris également, vêtus également, enseignés également, l'ćgalité sera, pour les jeunes élèves, non une spécieuse théorie, mais une pratique continucllement effective $"$.

(76) Ibid., p. 35 .

(77) Ibid., p. 15.

(78) Ibid., Tome V, Séance du 10 janvier 1793 , p. 208 : "Le but de la société civile est de développer les facultés naturelles de l'homme pour lc bonheur des individus et de la société entière. Le seul moyen d'attcindre ce but, c'est l'accord de l'intérêt privé avec l'intérêt général ; c'est la direction des passions du cour humain vers les objets utiles à la prospérité publique ".

(79) Ibid., tome X, Sur le plan d'éducation nationale de Michel Lepeletier (29 juillet 1793), p. 20. 
ces enfants abandonnés à l'État devra être de surcroît marquée du sceau de la frugalité : « Je désire que pour les besoins ordinaires de la vie, les enfants privés de toute espèce de superfluité, soient restreints à l'absolu nécessaire. Ils seront couchés durement, leur nourriture sera saine, mais frugale ; leur vêtement commode, mais grossier $\aleph^{80}$. Enfin, s'il subsistait un doute quant à l'inspiration d'un tel projet, il reste à porter le regard sur le contenu physique de cette éducation : "Nos premiers soins se porteront sur la portion physique de l'éducation. Former un bon tempérament aux enfants, augmenter leurs forces, favoriser leur croissance, développer en eux vigueur, adresse et agilité ; les endurcir contre la fatigue, les intempéries des saisons, la privation momentanée des premiers besoins de la vie ${ }^{81}$. Sur ce point Lepeletier voudrait que l'effort soit maintenu chez les adolescents et les adultes, car la nation peut toujours en tirer profit. Il aimerait également, par ce moyen, entretenir une émulation constante entre les citoyens. Dans cette optique, Lepeletier rejoint volontiers le concept de fêtes nationales, cher à Robespierre, durant celles-ci chacun pourrait montrer sa valeur dans des épreuves que nous qualifierions aujourd'hui de sportives ${ }^{82}$.

En dehors de ces activités dont la finalité militaire est probable, Lepeletier souhaite habituer les jeunes à l'effort par un travail manuel approprié ${ }^{\times 3}$ : "Après la force et la santé, il est un bien que l'institution publique doit à tous [...] l'accoutumance au travail [...] mais j'entends en général ce courage pour entreprendre une tâche pénible, cette action en l'exécutant, cette constance à la suivre, cette persévérance jusqu'à ce qu'elle soit achevée, qui caractérise l'homme laborieux ${ }^{84}$. Ce n'est pas l'épanouissement des enfants qui est ici en cause, mais l'intérêt de l'État.

(80) lbid., p. 20 et 25 : « Il importe que pour tous, l'habitude de l'enfance soit telle, qu'aucun n'ait à souffrir du passage de l'institution aux divers états de la société. Lenfant qui rentrera dans le sein d'une famille pauvre, retrouvera toujours ce qu'il quitte ; il aura été accoutumé à vivre de pcu, il n'aura pas changé d'existence; quant à l'enfant du riche, d'autres habitudes plus douces lattendent, mais celles-là se contractent facilement. Et pour le riche lui-même, il peut exister dans la vie telles circonstances où il bénira l'âpre austérité et la salutaire rudesse de l'ćducation de ses premicrs ans. [...] Diminuer les nécessités de l'indigence, diminuer le superflu de la richesse, $c$ 'est un but auquel doivent tendre toutes nos institutions".

(81) Ibid., p. 14, 19 et 20 : " Je me plains qu'un des objets les plus essentiels de l'éducation est omis : le perfectionnement de l'être physique. Je sais qu'on propose quelques exercices de gymnastique : cela est bon : mais cela ne suffit pas. Un genre de vie continu, une nourriture saine et convenable à l'enfance, des travaux graduels et modérés, des épreuves successives mais continuellement répétées, voilà les seuls moyens de créer des habitudes; voilà les moyens efficaces de donner au corps tout je développement et toutes les facultés dont il cst susceptible ».

(82) Ihid., p. 34 : « La semaine apparticnt au travail, les en détourner serait absurde et impossible ; mais aux jours de délassement à certaines époques qui scront déterminées, il est bon, il est convenahle que la jeunesse retrouve des exercices du corps. Quelques leçons, des fêtes, des rassemblements qui appellent son attention, intéressent sa curiosité, excitent son émulation. Ainsi les heureuses impressions qu'aura reçues l'enfance ne s'effaceront point; et sans rien dérober du temps nécessaire aux travaux, le repos cessera d'être oisif ct le plaisir lui-même présentera des instructions ".

(83) Ibid., p. 21 : «J'ai regardé cette partie de l'éducation comme une des plus importantes. Dans l'emploi de la journée tout le reste sera accessoire, le travail des mains sera la principale occupation ».

(84) Ibid., p. 20. 
Léducation ne doit porter que sur l'affermissement de qualités utiles à la nouvelle société : "Formez de tels hommes, et la République composée bientôt de ces robustes éléments, verra doubler dans son sein les produits de l'agriculture et de l'industrie. Formez de tels hommes, et vous verrez disparaitre presque tous les crimes. Formez de tels hommes, et l'aspect hideux de la misère n'affligera plus vos regards. Créez dans vos jeunes élèves ce goût, ce besoin, cette habitude du travail, leur existence est assurée, ils ne dépendent plus que d'eux-mêmes $"^{\mathrm{x}}$. À la différence du législateur spartiate, Lepeletier, suivant en cela Mably et Rousseau, assigne une place importante à l'activité agricole au sein même de l'éducation. Il ne s'agit plus de ne former que des soldats, mais le souci demeure néanmoins de former des citoyens obéissants et disciplinés ${ }^{86}$. Lapprentissage de l'obéissance aux lois et aux magistrats sera initié par l'instauration de petits chefs parmi les groupes d'enfants. La méthode est une nouvelle illustration du retour aux institutions spartiates. La discipline et l'émulation sont les maitres-mots de cette éducation ${ }^{87}$.

La formation de l'intellect dans le plan de Lepeletier n'intervient que de façon secondaire, encore qu'elle soit elle aussi orientée dans un sens particulier. En effet Lepeletier estime que dans cet âge tendre il n'est pas temps d'enseigner les sciences et les arts, ce qu'il faut c'est former des mours. Ainsi, l'éducation, telle qu'elle est ici entendue, doit se concentrer sur les grands principes à inculquer aux jeunes républicains, elle sera donc fortement empreinte de morale. On apprend des attitudes et des comportements : «Sans l'éducation nationale, il vous faut aussi renoncer à former ce que j'appelle les moeurs de l'enfant, qui bientôt, par ce plan, vont devenir les mœurs nationales; et par là je veux dire la sociabilité ; son caractère, un langage qui ne soit point grossier, l'attitude et le port d'un homme libre, enfin les manières franches, également distantes de la politesse et de la rusticité. Entre citoyens égaux d'une même République, il faut que ces divers avantages de l'éducation soient répartis à tous : car on a beau dire, ces nuances, lorsqu'elles existent, créent d'incalculables différences et établissent de trop réelles inégalités entre les hommes ${ }^{88}$. Au sortir de cette institution, l'adolescent français devra ressembler à son lointain cousin lacédémonien idéalisé : il sera frugal, honnête, juste et prêt à toutes les

(85) Ibid.

(86) Ibid. : “ Régler sa vie, se plier au joug d'une exacte discipline, sont encore deux habitudes importantes au bonheur de l'être social. Elles ne peuvent se prendre que dans l'enfance [...] On calculerait difficilement à quel point une vie réglée et bien ordonnée $[. .$.$] moralise les actions de lhomme, fait entrer$ dans sa conduite ce qui est bien et la remplit tellement d'actes utiles, qu'il ne reste plus de place, si je puis parler ainsi, pour tout ce qui est vice ou désordre $"$.

(87) Ibid., p. 18 : « Je trouve beaucoup d'avantages à établir dans la petite troupe enfantine ces espèces de grades; ils seront propres à faciliter l'exécution de tous les détails, et à y maintenir une exacte discipline ".

(88) Ibid., p. 22. 
grandes actions en faveur de sa patrie ${ }^{89}$. Le mot régénération prend ici tout son sens, on rompt avec l'idéologie machiavélienne, très en vogue depuis l'affirmation de la monarchie absolue, qui aurait corrompu les cours et les esprits. Ce courant révolutionnaire qui place la morale sur un piédestal ne semble pas être un prolongement de l'idéal chrétien, il apparait plutôt comme l'aboutissement d'une longue tradition, propre à la pensée politique française, initiée par Montaigne, reprise et poursuivie par Fénelon, Mably et Rousseau, s'inscrivant dans une opposition à une certaine forme du pouvoir royal.

En dehors de cet aspect, Lepeletier ne juge pas nécessaire d'étendre l'objet de l'éducation au-delà des connaissances strictement nécessaires à ses fins, à savoir, lire, écrire, compter, ainsi que quelques notions « d'économie domestique et rurale ". Il pense également pouvoir tirer profit, pour la république, des « récits des peuples libres et de la Révolution française " . Les anciens thuriféraires de Sparte avaient déjà relevé cette particularité de l'éducation de cette cité. Ils louaient Lycurgue d'avoir empli les jeunes esprits des exploits réels ou légendaires de leurs ancêtres, gonflant ainsi leur fierté et leur désir de maintenir une réputation qui se noie dans les temps homériques. Le respect des anciens n'est pas non plus une préoccupation étrangère au plan de Lepeletier. Il place les vieillards au cour de son dispositif : "Formons une réunion doublement utile : je voudrais que les vieillards à la charge des communes d'un canton trouvassent leur asile dans une partie des établissements destinés à l'institution publique. [...] Ainsi le saint respect pour la vieillesse, la compassion pour le malheur, la bienfaisante humanité, pénétreront l'âme de nos élèves avec leurs premières sensations, s'y graveront profondément ; leurs habitudes mêmes deviendront en eux des vertus ${ }^{91}$. Les anciens ont une sorte de fonction de passage, ils représentent auprès de la jeunesse la pérennité des institutions. Lepeletier semble viser le long terme car la France ne peut, à cette époque, se targuer d'une longue tradition républicaine. Néanmoins, cela révèle sa compréhension du processus de légitimation d'un régime qui ne peut se faire que par l'action du temps.

Robespierre, quant à lui ne trouve rien à redire sur le plan dont il fait la lecture. Peut-être l'a-t-il lui-même remanié et interprété, mais rien ne permet de l'affirmer. Le projet qu'il présente n'est qu'une mise en forme des idées de Lepeletier. Larticle IV, par exemple, reprend mot pour mot des passages du plan d'éducation : "L'objet de l'éducation nationale

(89) Ibid. : “ Je ne sais si je m'abuse, mais il me semble que toutes les habitudes dont j’ai présenté jusqu'ici l'énumération, sont une source féconde d'avantages pour les enfants et pour l'État ; ce sont les vrais fondements d'une salutaire éducation ; sans elles il n'existe pas d'éducation. Si dans l'enfance, nous ne les donnons point à tous les citoyens, la nation ne peut pas être profondément régénérée ».

(90) Ibid., p. 22 et 23.

(91) Ibid., p. 31. 
sera de fortifier le corps des enfants, de le développer par des exercices de gymnastique, de les accoutumer au travail des mains, de les endurcir à toute espèce de fatigue, de former leur cœur et leur esprit par des instructions utiles, et de leur donner les connaissances nécessaires à tout citoyen, quelle que soit sa profession $n^{42}$. Robespierre n'ajoute que des modalités pratiques. Il fait état des questions qui restent à régler, comme la conception des nouveaux manuels ${ }^{\text {p3 }}$ et tout ce qui a trait au mode de vie communautaire préconisé dans le plan : les exercices physiques, les travaux manuels, l'emploi du temps des enfants, leur nourriture, leur habillement... ${ }^{34}$ La retranscription article par article du projet de Lepeletier démontre la sincère volonté de Robespierre d'instaurer cette éducation exclusivement étatique. Le moule spartiate qu'il se défendait de vouloir appliquer au modèle français est bien présent.

Robespierre ne fait certes pas systématiquement référence à Sparte dans toutes ses interventions, mais on peut constater que son appréciation de la cité de Lycurgue est largement positive, et que seuls les impondérables de son époque l'empêchent d'en faire son parangon politique. C'est dans sa pensée qu'on mesure sans doute le plus l'impact de l'œuvre de Rousseau sur les hommes de la Révolution. Lauteur du Contrat social, des Discours sur l'inégalité ou sur les sciences et les arts, semble omniprésent. Mais lui-même, sur bien des points ne fait que transmettre une tradition antique, tant il est imbibé, comme d'autres avant lui, des écrits de Plutarque. C'est donc sous la Convention pré-thermidorienne que Sparte fait son retour le plus éclatant, avec quelques esquisses de réalisations. Cependant, elle atteint aussi là son apogée, et tombera en discrédit avec le régime qui l'a élevée. En effet, après Robespierre, Lacédémone cesse d'alimenter la pensée politique. Certes on pouvait lire encore quelques réminiscences chez Babeuf et les "Égaux ", mais cet exemple n'est plus qu'une illustration comme une autre, à laquelle on préfère bien souvent Rome, et plus tard Athènes et sa démocratie, enfin perçue sous un jour favorable. $\mathrm{Si}$ pour Robespierre "Sparte brille comme un éclair dans des ténèbres immenses », déjà Saint-Just, l'ami fidèle, considérait lui que « le monde est

(92 lbid., "Projet de décret sur l'éducation nationalc par le citoyen Robespierre » op. cit., p. 35.

(93) Ibid., p. 41 : « Livres élémentaires à composer [...] Principes sommaires de la constitution, de la morale, de l'économie domestique et rurale ; récits des faits les plus remarquables de l'histoire de peuples libres et de la Révolution française : le tout divisé par leçons propres à exercer la mémoire des enfants, et à développer en eux le germe des vertus civiles et des sentiments républicains".

(94) Ibid., p. 42 : "Questions à résoudre. $1^{\circ}$ Quelle est la forme d'habillement complet des enfants de l'un et de l'autre sexe, le plus commode et le plus économique ? [...] $2^{\circ}$ Quels sont les divers genres d'aliments les plus convenables aux enfants de cinq à douze ans, et en même temps les plus économiques? [...] $3^{\circ}$ Quels sont les soins et attentions physiques propres à conserver et à fortifier la santé des enfants ? Quels sont les exercices de gymnastique les plus propres à favoriser leur croissance, développer les muscles, et leur donner force, adresse et agilité... ". 
vide depuis les Romains ». La réaction thermidorienne et le développement de la pensée libérale enterre les lois de Lycurgue. Une citation de Victor Hugo analyse parfaitement le phénomène : "Ce siècle avait deux ans ! Rome remplaçait Sparte, déjà Napoléon perçait sous Bonaparte".

Il est vrai qu'à la fin du XIX' siècle et dans la première moitié du $\mathrm{XX}^{c}$, Sparte entre à nouveau dans le champ de la pensée politique. Elle est évoquée par les extrêmes droites françaises et allemandes, ouvrant des perspectives malheureuses, mais ce n'est pas la même citées. La source a changé. Ce n'est plus à travers Plutarque qu'on aborde Lacédémone ; il est remplacé par les très anciens poètes grecs des $\mathrm{VII}^{\mathrm{e}}$ et $\mathrm{VI}^{\mathrm{e}}$ siècles avant notre ère, Tyrthée, Alcman, Bacchylides ou Pindare. Ainsi on ne se réfère plus au législateur mythique, à ses lois et ses institutions ${ }^{46}$, on préfère magnifier un peuple qui aurait su s'élever par ses qualités intrinsèques. Le concept de race s'est substitué à celui de loi.

Maxime Rosso

Université Paul Cézanne (Aix-Marseille III) Faculté de Droit et de Science Politique, UFR Droit

Cité douanière

1 rue Turenne

13110 Port-de-Bouc marie.max@infonie.fr

(95) Voir notamment le Voyage de Sparte de Maurice Barrès.

(96) Ce qui renforce la thèse de ceux qui prétendent que l'histoire de Lycurgue est une légende inventée au V'siècle afin de légitimer le régime et les lois de Lacédémone. 